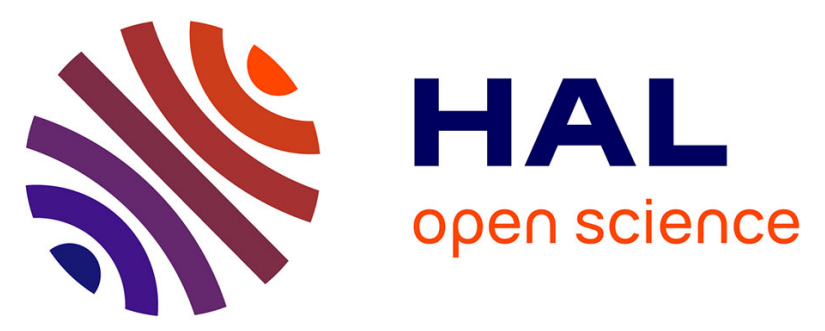

\title{
Bimetallic Cu-Rh Nanoparticles on Diazonium-Modified Carbon Powders for the Electrocatalytic Reduction of Nitrates
}

Peyman Mirzaei, Stéphane Bastide, Atieh Aghajani, Julie Bourgon, Eric M. Leroy, Junxian Zhang, Youssef Snoussi, Asma Bensghaier, Ouezna Hamouma, Mohamed M Chehimi, et al.

\section{To cite this version:}

Peyman Mirzaei, Stéphane Bastide, Atieh Aghajani, Julie Bourgon, Eric M. Leroy, et al.. Bimetallic $\mathrm{Cu}$-Rh Nanoparticles on Diazonium-Modified Carbon Powders for the Electrocatalytic Reduction of Nitrates. Langmuir, 2019, 35 (45), pp.14428 - 14436. 10.1021/acs.langmuir.9b01911 . hal-03097529

\author{
HAL Id: hal-03097529 \\ https://hal.science/hal-03097529
}

Submitted on 5 Jan 2021

HAL is a multi-disciplinary open access archive for the deposit and dissemination of scientific research documents, whether they are published or not. The documents may come from teaching and research institutions in France or abroad, or from public or private research centers.
L'archive ouverte pluridisciplinaire HAL, est destinée au dépôt et à la diffusion de documents scientifiques de niveau recherche, publiés ou non, émanant des établissements d'enseignement et de recherche français ou étrangers, des laboratoires publics ou privés. 


\title{
Bimetallic $\mathrm{Cu}-\mathrm{Rh}$ nanoparticles on diazonium-modified carbon powders for the electrocatalytic reduction of nitrates
}

Peyman Mirzaei ${ }^{1,2}$, Stéphane Bastide ${ }^{1}$, Atieh Aghajani ${ }^{2}$, Julie Bourgon ${ }^{1}$, Éric Leroy ${ }^{1}$, Junxian Zhang $^{1}$, Youssef Snoussi ${ }^{1,3}$, Asma Bensghaier ${ }^{1,4}$, Ouezna Hamouma ${ }^{1,5}$, Mohamed M. Chehmi ${ }^{1, *}$, Christine Cachet-Vivier ${ }^{1, *}$

${ }^{1}$ Université Paris Est, ICMPE (UMR 7182), CNRS, UPEC, F-94320 Thiais, France.

${ }^{2}$ MBA Water Treatment Chemicals Co., Ltd, N9 Tadayyon Alley, Shariati St., Tehran, Iran.

${ }^{3}$ Laboratory of Materials, Molecules and Applications, IPEST, University of Carthage, Sidi Bou Said road, B.P. 512070 , La Marsa, Tunisia.

${ }^{4}$ Université de Tunis El Manar, Faculté des Sciences de Tunis, Laboratoire de Chimie (Bio)Organique Structurale et de Polymères - Synthèse et Etudes Physicochimiques (LR99ES14), 2092 El Manar, Tunisia,

${ }^{5}$ Laboratoire d'Electrochimie, Corrosion et de Valorisation Énergétique (LECVE), Faculté des Sciences Exactes, Université de Bejaia, 06000 Bejaia, Algeria.

Corresponding authors: C. Cachet-Vivier, cachet@icmpe.cnrs.fr

M. M. Chehimi: chehimi@icmpe.cnrs.fr

\begin{abstract}
4-benzenethiol-functionalized High Surface Area Graphite powder was prepared and decorated with bimetallic $\mathrm{Cu}_{100-\mathrm{x}} \mathrm{Rh}_{\mathrm{x}}$ nanoparticles (NPs) to serve as electrocatalysts for the reduction of nitrates. In the first step, the HSAG powder was grafted with in situ generated diazonium compounds from 4-aminothiophenol (ATP), in acidic medium using $\mathrm{NaNO}_{2}$ for the diazotization process. The surface composition was tuned using different initial quantities of ATP. The surface XPS-determined S/C atomic ratio was found to increase stepwise with the initial amine quantity. In a second step, the grafted and untreated HSAG powders were decorated with $\mathrm{Cu}_{100-\mathrm{x}} \mathrm{Rh}_{\mathrm{x}} \mathrm{NPs}$ by a wet chemical method and the elemental composition of the end composites assessed by EDS-SEM and ICP, whereas TEM and EDS-TEM served to characterize the NPs morphology and their composition at the nanometer scale. In all cases, the NP size was invariably found to be $\sim 1.7 \mathrm{~nm}$ but with a size distribution becoming narrower under increasing grafting rate and the global composition enriched in copper. Voltammetry was performed with a cavity microelectrode to evaluate the electrocatalytic performances of the composites for nitrate reduction. Increasing diazonium grafting led to a progressive reduction of the peak current intensity and a shift of the peak potentials towards cathodic values. Maximum intensity was obtained for $0.005 \mu \mathrm{mol}$ of diazonium salt per mg of HSAG,
\end{abstract}


with a gain of $40 \%$ in comparison to the best untreated sample. This improvement and a change of the voltammogram characteristics after grafting seem to result from modifications of the local composition at the level of NPs that differs from the global composition. This work conclusively shows that diazonium surface modification is important not only to attach electrocatalytic NPs to carbon supports but also to provide narrower size distribution of the electrocatalysts together with finely tuned catalytic properties.

Keywords: Carbon powder grafting, diazonium salt, copper-rhodium nanoparticles, nitrate electroreduction, cavity microelectrode.

\section{Introduction}

The electrocatalytic reduction of nitrates is considered as a promising alternative to biological or physical treatments used for wastewater remediation. Electrocatalysis emerged in recent years as a highly efficient, low-cost strategy to readily remove toxic species such as nitrates ${ }^{1,2}$. It is thus essential to design nanometer-scale catalysts with narrow size distribution and evenly dispersed on- or mixed with- electrode material supports such as $\mathrm{sp}^{2}$ carbon. As metallic nanocatalysts are high surface energy materials they tend to stick to each other and agglomerate in the case of mixing with the support ${ }^{3}$. An alternative consists in synthesizing in situ the nanocatalysts in the presence of the support. Although this procedure is simple and straightforward, agglomeration of the in situ generated nanocatalysts is likely to occur. This shortcoming could be solved using functionalized supports which complex the metal ions before their in situ reduction into immobilized catalytic metallic nanoparticles ${ }^{4-9}$. In the recent years, carbon nanomaterials were functionalized using a variety of ways such as thermal treatment of azides to provide nitrenes in the presence of carbon nanotubes ${ }^{10}$, DielsAlder [4+2] cycloaddition ${ }^{11}$, sulfonylation $^{12}$ or amidation $^{13}$.

Among the numerous compounds employed to modify (nano)materials, diazonium salts emerged as remarkable surface modifiers, particularly suitable for carbon (nano)materials such as carbon nanotubes ${ }^{14}$ and serve as coupling agents for the robust attachment of nanoparticles to surfaces ${ }^{15,16}$. The rationale for using diazonium compounds for this purpose lies in their ability to readily react with $\mathrm{sp}^{2}$ carbon (nano)materials without any reducing agent ${ }^{17-19}$ which facilitates the decoration of supports by functional nanomaterials and other ultrathin coatings ${ }^{20-23}$. Particularly, in the domain of (electro)catalysis, the immobilization of nano- 
catalysts on modified carbon nanotubes (CNTs) has been explored by Guo and $\mathrm{Li}^{24}$ and others and reviewed by Compton and co-workers ${ }^{3}$. For example, Guo and $\mathrm{Li}^{24}$ have explored this way for the first time with the in situ synthesis of silver CNTs grafted with a monolayer of 4-aminophenyl groups via the electrochemical reduction of the corresponding nitrobenzenediazonium salt. Then, they electrochemically reduced the nitro groups to the corresponding amine. Afterwards a silver salt was adsorbed on the aminophenyl monolayer and silver NPs were generated for the electrocatalysis of methanol oxidation. In a similar way, palladium NPs $(2.5 \mathrm{~nm})$ were produced via a potentiostatic reduction and tested for hydrazine electro-oxidation and demonstrated a higher electro-activity than the non-grafted samples. Another work ${ }^{25}$ described a protocol for the immobilization of copper nanoparticles on grafted surfaces consisting to reduce a $\mathrm{CuSO}_{4}$ salt by $\mathrm{NaBH}_{4}$ in presence of a surfactant. Recently, graphene has attracted much attention as support for metallic nanocatalysts. Its diazonium modification permitted to immobilize palladium nanocubes and the end modified graphene/catalyst served for the electrooxidation of formic acid. ${ }^{26}$

As far as Vila et al ${ }^{27}$ are concerned, they have studied bimetallic electrocatalysts for an application in nitrate electroreduction. In a first step, the carbon was grafted with sulfonate groups by the electroreduction of the corresponding diazonium compound. In a second step, copper ions were adsorbed on the modified surface and reduced to metallic copper by electrochemical reduction. Copper-platinum based material were then obtained by the replacement of copper by immersion in a $\mathrm{K}_{2} \mathrm{PtCl}_{6}$ aqueous solution through a redox reaction between $\mathrm{Cu}(0)$ and $\mathrm{Pt}(\mathrm{IV})$. Various compositions were obtained for different reaction times. Afterwards the materials were tested for nitrate electroreduction, however no synergistic effect was observed for this bimetallic system.

Bimetallic materials are particularly interesting for the electrochemical reduction of nitrate due to synergistic effects occurring between the two metals ${ }^{1}$. Among all possible metal combinations, Comisso et al. ${ }^{28}$ have shown the interest of the copper-rhodium system by synthesizing electrodeposited films with different compositions $\mathrm{Cu}_{100-\mathrm{x}} \mathrm{Rh}_{\mathrm{x}}$ ( $\mathrm{x}$ being the atomic $\%$ of rhodium). They found that the higher electrocatalytic activity was obtained for $\mathrm{Cu}_{30} \mathrm{Rh}_{70}$, with a current intensity slightly lower than that on copper (factor 0.86 ) but with a gain in potential of $\sim 300 \mathrm{mV}$ by comparison with copper and a gain in intensity of 5.4 times by comparison with rhodium. Recently, some of us have studied composites consisting of nanoparticles (NPs) of rhodium, copper and $\mathrm{Cu}_{100-\mathrm{x}} \mathrm{Rh}_{\mathrm{x}}$ in a high-surface area graphite ${ }^{29}$. It The best composite, obtained for the composition $\mathrm{Cu}_{48} \mathrm{Rh}_{52}$, was 7.5 times more effective than pure rhodium. was possible to obtain ultra-small nanoparticles with an average diameter $\sim 2$ 
$\mathrm{nm}$, however, some agglomerates were observed during TEM observations. An envisaged approach for improving the dispersion of the NPs is to firstly functionalize the carbon surface and then to produce the NPs on this modified surface. This is the rationale we have adopted and tested based on the composite with the highest catalytic efficiency (i.e. $\mathrm{Cu}_{48} \mathrm{Rh}_{52} / \mathrm{HSAG}$ ).

Herein, we take advantage of the surface chemistry of diazonium salts to modify HSAG powder particles in order to have a reactive platform for the in-situ deposition of bimetallic $\mathrm{Cu}_{100-\mathrm{x}} \mathrm{Rh}_{\mathrm{x}}$ nanoparticles. We have reasoned that the facile functionalization of carbon materials with diazonium salts will serve not only to anchor the bimetallic nanoparticles but also to disperse them evenly on the surface of the support, an issue that has not been envisioned in our previous work. One key issue of the present study is the tuning of dispersion state of the nanocatalyst and of their electrocatalytic activity. Although, metallic nanocatalysts were coated on diazonium-modified electrode materials in a variety of innovative strategies $3,24,30,31$, to the very best of our knowledge this work is unique in the sense that (i) it tackles the modification of HSAG prior to decoration with bimetallic and not with single metal nanoparticles, (ii) it concerns HSAG and not the costly CNTs, and (iii) it aims at addressing the environmental issue of nitrates in water with high performance composite catalysts with finely tuned catalytic features. All in one, this paper combines the best of two worlds: evenly dispersed nanocatalysts on diazonium-modified HSAG and electroreduction of nitrates. This is what has motivated this investigation.

\section{Experimental}

Grafting procedure and XPS analyses. A high surface area carbon powder HSAG500 from Imerys Graphite \& Carbon was beforehand grafted via the procedure schemed in Figure 1. For the sake of clarity, only monomolecular grafting is schematically shown, whereas aryl oligomers are likely to form ${ }^{32}$ as indisputably demonstrated by time of flight secondary ion mass spectroscopy ${ }^{33}$.

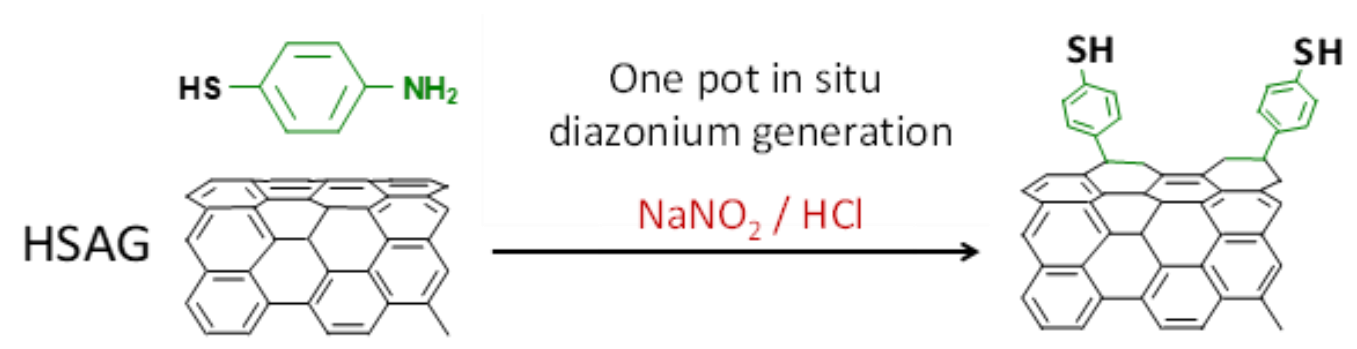

Figure 1. Scheme of the one pot synthetic route used for grafting benzenethiol groups on HSAG. 
A series of samples has been synthesized with different grafting rate expressed as the ratio between the number of mole of 4-Aminothiophenol (ATP) per mg of HSAG used: 0, $0.005,0.05,0.5$ and $3.3 \mathrm{ATP} / \mathrm{HSAG}(\mu \mathrm{mol} / \mathrm{mg})$.

The detailed chemical procedure for grafting is as follows: $200 \mathrm{mg}$ of HSAG carbon are dispersed in $50 \mathrm{~mL}$ of water under sonication for 5-10 minutes. To this dispersion, an ATP solution is added, that is prepared by dissolving an appropriate amount of ATP in $5 \mathrm{~mL}$ of $37 \% \mathrm{HCl}$ (corresponding to the chosen ratio ATP/HSAG). The mixture is sonicated for 5-10 minutes and then placed in an ice water bath. A cooled solution of $\mathrm{NaNO}_{2}$ is then added at a concentration equal to the ATP concentration. The reaction is carried out under agitation for one hour and then the suspension is centrifuged to recover the grafted HSAG. It is washed 5 times and then dried in an oven at $60^{\circ} \mathrm{C}$. The powder is then ready for XPS analysis and to be decorated with nanoparticles. This simple and efficient "beaker chemistry" procedure permits to prepare aryl-modified HSAG powder particles in high yield, for further in situ deposition of nanocatalysts, insertion in the cavity microelectrode and finally electrocatalytic testing.

Surface composition of the HSAG samples was determined by XPS using a K Alpha apparatus (Thermo, East Grinstead, UK) fitted with a monochromatic Al K $\alpha$ X-ray source $(\mathrm{h}=1486.6 \mathrm{eV})$. Experimental parameters were the following: $\mathrm{X}$-ray spot size $=400 \mu \mathrm{m}$; pass energy $=80 \mathrm{eV}$ (narrow regions) and $200 \mathrm{eV}$ (survey spectra); step size $=0.1 \mathrm{eV}$ (narrow regions) and $1 \mathrm{eV}$ (survey regions); dwell time $=100 \mathrm{~ms}$. The compositions were determined using the manufacturer's sensitivity factors. Given the X-ray spot size of $400 \mu \mathrm{m}$, we assume that XPS gives a good average surface composition of the HSAG particles (modified with aryl groups and post-decorated with nanocatalysts).

Synthesis of the (bi)metallic NPs/HSAG composites. Composites of $\mathrm{Cu}_{100-\mathrm{x}} \mathrm{Rh}_{\mathrm{x}}$ nanoparticles (with $x$ the atomic percent (at.\%) of rhodium) dispersed in non-grafted/grafted carbon were synthesized via a wet chemical synthesis described in detail elsewhere ${ }^{29}$. Briefly, the chemical synthesis of the nanoparticles consists to impregnate $75 \mathrm{mg}$ of the carbon powder by $18 \mathrm{~mL}$ of an aqueous metal salts solution containing a mixture of $\mathrm{RhCl}_{3}$ and $\mathrm{CuSO}_{4}$ salts in presence of a surfactant CTAB (Cetyl Trimethyl Ammonium Bromide), the $\mathrm{pH}$ of the solution being adjusted at 2 .

Five samples were prepared under Condition 1: $2.5 \mathrm{mmol} \mathrm{L}^{-1} \mathrm{RhCl}_{3}$ and $2.5 \mathrm{mmol} \mathrm{L}^{-1}$ $\mathrm{CuSO}_{4}$, i.e. the one allowing the composition $\left(\mathrm{Cu}_{48} \mathrm{Rh}_{52}\right)$ that gives the highest electrocatalytic current in the absence of grafting. These samples were obtained with HSAG carbon with different grafting rates (at $0,0.005,0.05,0.5$ and $3.3 \mathrm{ATP} / \mathrm{HSAG}, \mu \mathrm{mol} / \mathrm{mg}$ ). Because we 
found out that using grafted HSAG and Condition 1 bimetallic NPs with a richer copper content were obtained, a sixth sample was synthesized with non-grafted HSAG under Condition 2: $2 \mathrm{mmol} \mathrm{L}^{-1} \mathrm{RhCl}_{3}$ and $3 \mathrm{mmol} \mathrm{L}^{-1} \mathrm{CuSO}_{4}$ ), to allow the comparison between grafted and non-grafted HSAG for bimetallic NPs of the same composition.

In both conditions, the metal mass fraction in the composite is expected to be $10 \mathrm{wt} \%$. After the impregnation step, a $0.1 \mathrm{~mol} \mathrm{~L}^{-1} \mathrm{NaBH}_{4}$ aqueous solution is added to the mixture to reduce metal ions $\mathrm{Rh}(\mathrm{III})$ and $\mathrm{Cu}(\mathrm{II})$ respectively to $\mathrm{Rh}(0)$ and $\mathrm{Cu}(0)$. The composite is then washed with water, rinsed with ethanol and dried at $60^{\circ} \mathrm{C}$.

Structural characterization and determination of the composition. A series of grafted samples (at $0,0.005,0.05,0.5$ and $3.3 \mathrm{ATP} / \mathrm{HSAG}, \mu \mathrm{mol} / \mathrm{mg}$ ) leading to various metal compositions. ICP-OES measurements were performed with a Varian Vista-Pro to determine in each case the metal content and composition. For that purpose, the composites $(20 \mathrm{mg})$ are treated overnight in Aqua Regia ( $3 \mathrm{~mL} \mathrm{HCl} \mathrm{37 \%}+1 \mathrm{~mL} \mathrm{HNO}_{3} 65 \%$ ) under sonication in a closed PTFE vial at $130^{\circ} \mathrm{C}$ to oxidize and solubilize the metals. The HSAG powder is filtered out and the filtrate is completed at $100 \mathrm{~mL}$ with water before analysis.

Scanning Electron Microscopy (SEM) images and Energy Dispersive X-ray Spectroscopy (EDS) were obtained with a Merlin FEG microscope from Zeiss equipped with AZtec systems (EDS Advanced, HKL Advanced Nordlys Nano, Oxford Instruments). The bimetallic composition was also estimated by EDS performed under the scanning mode over $90 \mu \mathrm{m}^{2}$ of the composite powders spread out on carbon tape, at $10 \mathrm{kV}$ and $150 \mathrm{pA}$.

Microstructural observations were performed by Transmission Electron Microscopy (TEM) with a $200 \mathrm{kV}$ FEG TEM (FEI Tecnai F20 equipped with a Gatan CCD Camera Orius 1000 , point to point resolution $0.24 \mathrm{~nm}$ ). The mean NP size has been determined by statistical analyses of several TEM images using the software Image ${ }^{34}$. Elemental characterization of nanoparticles was performed by Energy Dispersive Spectroscopy (EDS) with an EDAX Octane an EDAX Octane T Optima windowless SDD detector and the EDAX TEAM software. The quantification was made by means of the Cliff-Lorimer method ${ }^{35}$.

Electrochemical characterization. Electrochemical measurements were carried out with a classical 3-electrode cell using an Autolab PGSTAT 30 potentiostat. The working electrode was either a latex electrode, also called macroelectrode, either a homemade cavity microelectrode (CME), with a platinum wire (diameter $50 \mu \mathrm{m}$, depth $70 \mu \mathrm{m}$ ) which fabrication and use is described elsewhere ${ }^{36}$. Elaboration of the latex electrode consists to prepare a 
film by mixing $81-83 \%$ of the composite and $17-19 \%$ of PTFE (PolyTetraFluoroEthylene) as binder, then to press $\sim 5 \mathrm{mg}$ of this film on an inox grid which is fixed on a gold wire as current collector.

A cavity microelectrode is a tool very well adapted to the composites investigated in this study since it allows working directly with powders free of binder. Thanks to its small dimensions, it is possible to achieve higher scanning rates than with latex electrodes (i.e. without ohmic distortion). The powder material is placed in the cavity by simple mechanical pressure of the electrode tip on the powder. After electrochemical experiments, the cavity is unloaded under sonication for 5 minutes in distilled water.

The counter electrode was a platinum wire. A KCl Saturated Calomel Electrode was used as reference electrode for the measurements but in the followings, potentials are expressed versus the Reversible Hydrogen Electrode (V/RHE). The electrolyte was a $0.1 \mathrm{~mol} \mathrm{~L}^{-1}$ $\mathrm{KOH}$ aqueous solution and the electrochemical experiments were carried out under argon atmosphere. In all cases, a few cyclic voltammograms (CV) were recorded until a stable response was obtained. Only the first stable $\mathrm{CV}\left(2^{\text {nd }}\right.$ or $3^{\text {rd }} \mathrm{CV}$ usually) is taken into account so as to avoid any parasitic signal (e.g. reduction of dioxygen trapped in HSAG or metal oxides traces).

CV normalization. To compare the EC response of the different samples, we apply a normalization procedure to correct both filling deviations and metal content differences in samples. For this purpose, we choose a sample as reference $\left(\mathrm{Cu}_{48} \mathrm{Rh}_{52}\right.$, non-grafted) for which we have determined the capacitive current (noted $\mathrm{i}_{\mathrm{C}-\mathrm{Ref}}$ ), related to the (non-grafted) surface area of HSAG cycling in the CME.

(i) For samples with non-grafted HSAG, the quantity of composite cycling in the voltammograms can then be normalized using the capacitive currents. Hence, the first correction consists to scale the measured voltammogram $\left(i_{M}\right)$ at the same capacitive current than the reference $\mathrm{Cu}_{48} \mathrm{Rh}_{52}$ (multiplication factor of $\left(i_{C \text {-Ref }} / i_{C \text {-Sample }}\right)$ ). The second correction consists to normalize at $10 \mathrm{wt} . \%$ the metal content for all samples (multiplication factor of $\left.\left(10 \mathrm{wt.} \% / w t . \%_{\text {Sample }}\right)\right)$. The metal content $\left(w t . \%_{\text {Sample }}\right)$ is determined by ICP (cf. Table 2$)$. Finally, the corrected current $i_{C}$ is given by:

$$
i_{C}=i_{M} \frac{i_{C-\text { Ref }}}{i_{C-\text { Sample }}} \frac{10 w t . \%}{w t . \%_{\text {Sample }}}
$$

(ii) For the samples with grafted carbons, the capacitive response is specific to each sample and the normalization cannot be performed directly. Measurements with latex macroelectrodes must be conducted to evaluate these differences in capacitive currents $\left(i_{C \text {-Latex }}\right)$ with 
precise amount of grafted HSAG so as to correct the CME responses accordingly. A correction is applied to the previous equation through a multiplication factor of $\left(i_{\text {C-Latex- }}\right.$

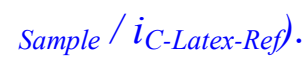

$$
i_{C}=i_{M} \frac{i_{C-\text { Ref }}}{i_{C-\text { Sample }}} \frac{10 w t . \%}{w t . \%_{\text {Sample }}} \frac{i_{C-\text { Latex-Sample }}}{i_{C-\text { Latex-Ref }}}
$$

\section{Results and discussion}

\subsection{Grafted surfaces analysis by means of XPS}

Figure 2 displays the survey (a) and high resolution S2p XPS spectra (b) of the composites. Figure 2(b) exhibits also the $\mathrm{S} / \mathrm{C}$ atomic ratio versus the initial ATP/HSAG ratio $(\mu \mathrm{mol} / \mathrm{mg})$, as inset (c).

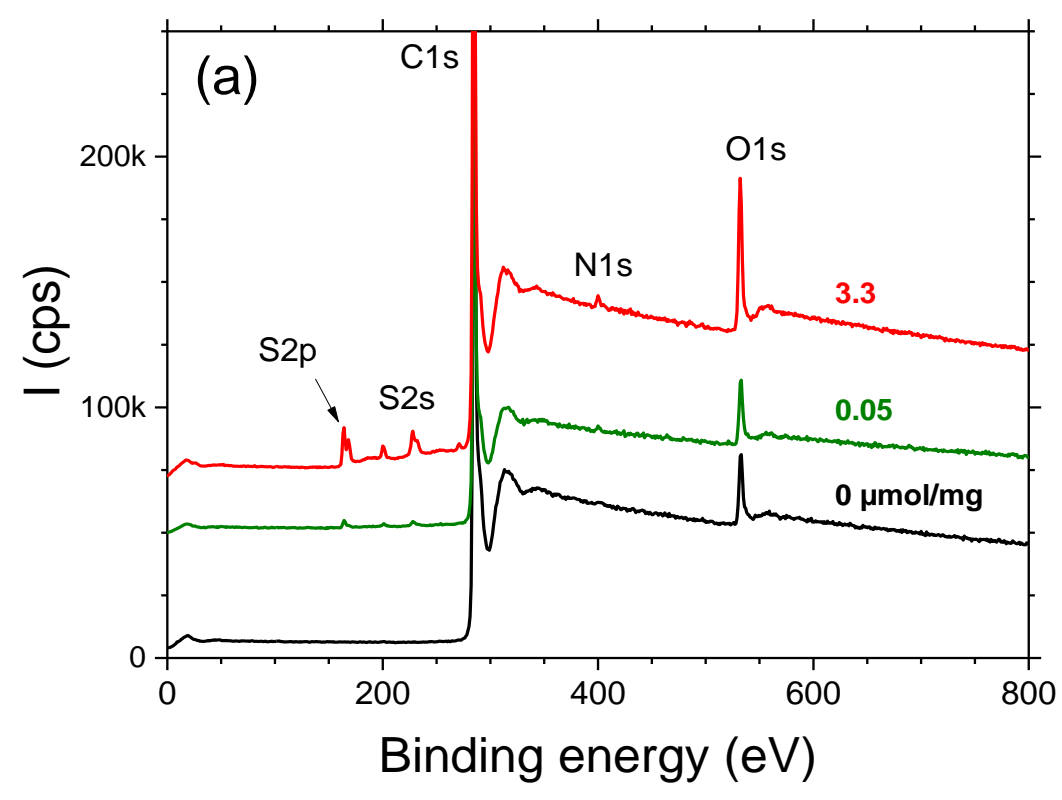




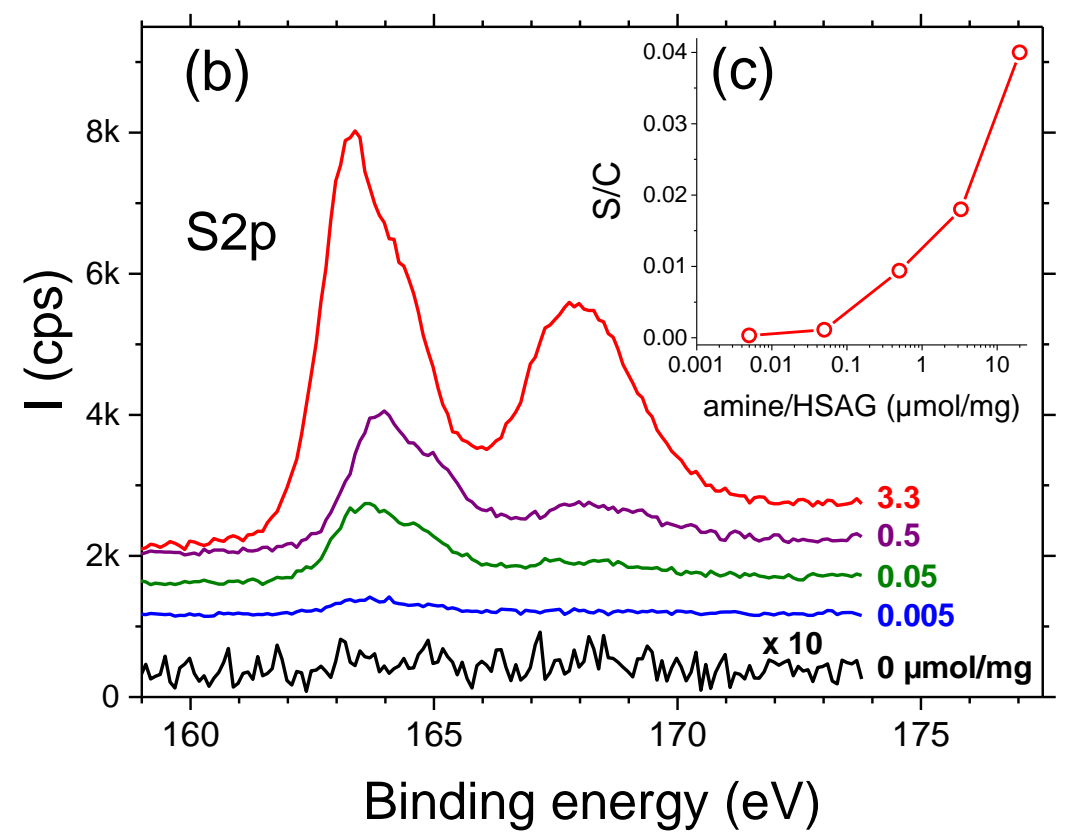

Figure 2. Surface analysis of untreated and diazonium-modified HSAG samples: (a) survey spectra, (b) high resolution $\mathrm{S} 2 \mathrm{p}$ spectra, and (c) surface $\mathrm{S} / \mathrm{C}$ atomic ratio (inset).

The survey regions show a prominent $\mathrm{C} 1$ s peak from the underlying HSAG centered at $285 \mathrm{eV}$ and a much less intense $\mathrm{O} 1 \mathrm{~s}$ peak due to the naturally occurring oxidation of $\mathrm{sp}^{2}$ carbon materials; herein the $\mathrm{O} 1 \mathrm{~s} / \mathrm{C} 1 \mathrm{~s}$ peak intensity ratio is similar to that reported elsewhere ${ }^{37}$. After attachment of the aryl groups, one can note small S2p and S2s features (at 164 and $229 \mathrm{eV}$, respectively) which account for the attachment of benzenethiol groups. It is also to note that at $400 \mathrm{eV}$ there is a noisy peak assigned to N1s, which most probably arises from azo $(-\mathrm{N}=\mathrm{N}-)$ bonds within the aryl layer ${ }^{38}$. This probably accounts for the formation of oligophenylene grafted to HSAG. The gradual attachment of the aryl layer to HSAG is also confirmed quantitatively after determination of the $\mathrm{S} / \mathrm{C}$ atomic ratio versus the initial concentration of ATP ( $c f$. Inset (c) of Figure 1). Indeed, Figure 2(b) shows very noisy and low intensity peaks for the S2p at the lowest ATP/HSAG ratio $(0.005 \mu \mathrm{mol} / \mathrm{mg})$; the peak has a much higher signal to noise ratio for the initial concentration of $3.3 \mu \mathrm{mol} / \mathrm{mg}$ employed to modify the HSAG. For the sake of clarity, the S2p feature corresponding to an initial concentration of diazonium $(20 \mu \mathrm{mol} / \mathrm{mg})$ is not displayed; the peak has indeed a high $\mathrm{S} / \mathrm{N}$ ratio. The $\mathrm{S} / \mathrm{C}$ intensity ratio increases steeply with the initial concentration of ATP, up to $3.3 \mu \mathrm{mol} / \mathrm{mg}$ and then more slowly ( $c f$. Figure 2(c); note the logarithmic scale of the $\mathrm{X}$-axis).

The S2p peak component at $\sim 168 \mathrm{eV}$ is most probably due to surface oxidation in the form of $-\mathrm{SO}_{3}{ }^{-}$resulting from air-exposure ${ }^{39}$ and/or to irradiation by X-rays during the surface analysis $^{40}$. 
Overall, the XPS analysis demonstrates that grafting of benzenethiol groups on HSAG is effective and can be varied progressively by changing the ATP/HSAG ratio.

As far as the immobilized bimetallic nanocatalyst is concerned, XPS analysis brings strong supporting evidence for the attachment of the nanocatalyst as displayed in Supporting Information Figure SI1 pertaining to the immobilization of $\mathrm{Cu}_{48} \mathrm{Rh}_{52}$ bimetallic nanocatalyst onto HSAG-SH prepared with an initial ATP/HSAG of $3.3 \mu \mathrm{mol} / \mathrm{mg}$. In Figure SI1a, Cu2 $\mathrm{p}_{3 / 2}$ exhibits a shake-up satellite characteristic of $\mathrm{Cu}$ (II) oxidation state, due to $\mathrm{CuO}$ and/or $\mathrm{Cu}(\mathrm{OH})_{2}$. The main $\mathrm{Cu} 2 \mathrm{p}_{3 / 2}$ peak has two contributions from the metallic state $\mathrm{Cu}(0)$ and $\mathrm{Cu}(\mathrm{II})$ at 932.5 and $934.2 \mathrm{eV}$, respectively ${ }^{41}$. The latter could be due to both $\mathrm{Cu}(\mathrm{OH})_{2}$ (peak expected at $934.8 \mathrm{eV}$ ) and $\mathrm{CuO}$, the $\mathrm{Cu} 2 \mathrm{p}_{3 / 2}$ peak of which is expected at $933.6 \mathrm{eV}^{41}$. The two peaks centred at 940.4 and $943.0 \mathrm{eV}$ are shake-up satellites that account for $\mathrm{Cu}(\mathrm{II})$.

The peak-fitted $R h 3 d$ doublet is best fitted with three $R h 3 d_{5 / 2}-R h 3 d_{3 / 2}$ doublets (in the intensity ratio $\sim 3: 2$, and peak position difference of 4.7-5 eV) centred at 306.7-311.4 eV; 308.2$312.9 \mathrm{eV}$ and 309.7-314.7 eV assigned to $\mathrm{Rh}(0)^{42,43}, \mathrm{Rh}(\mathrm{III})$ in $\mathrm{Rh}_{2} \mathrm{O}_{3}{ }^{43}$ and $\mathrm{Rh}(\mathrm{IV})$ in $\mathrm{RhO}_{2}{ }^{44}$.

Finally, Figure SI1c displays the peak-fitted S2p spectrum from a bimetallic nanocatalyst-coated HSAG grafted with thiophenyl groups. Interestingly, at low binding energy, there is a peak component at $162.9 \mathrm{eV}$ which accounts for thiolates at the HSAG-nanocatalyst interface. This is a clear indication of specific interactions between the aryl groups and the bimetallic nanocatalyst as previously reported for the attachment of gold nanoparticles onto thiophenyl-modified glassy carbon electrode ${ }^{45}$.

\subsection{Morphology of the bimetallic NPs}

Synthesized composites for different rates of grafting (ATP/HSAG ratio) have been examined by TEM ( $c f$. Figure SI-2 in the Supporting Information). A statistical analysis has been performed based on the measurement isolated (individual) NP size with a count number of $~ 300$ NPs for each sample (corresponding to 3 to 5 TEM images). This analysis is relevant regarding the production of individual NPs but does not take into account the existence of aggregates and their relative proportion between samples. Histograms calculated from this statistical analysis are shown in Figure 3. 


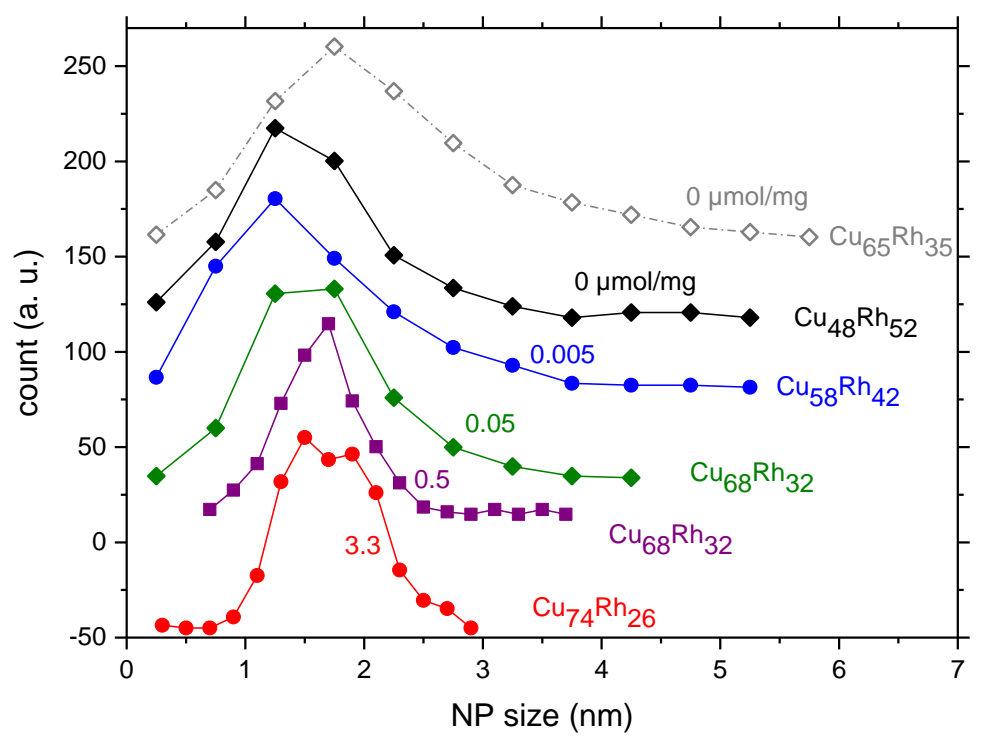

Figure 3. NP size histograms (peak distribution normalized at 100) determined from TEM images. The ATP/HSAG ratio $(\mu \mathrm{mol} / \mathrm{mg}$ ) and the bimetallic composition (global, ICP) are indicated.

The average diameter of (isolated) NPs and the standard deviation are reported in Table 1. All samples exhibit well dispersed nanoparticles with sizes lower than $2 \mathrm{~nm}$. Although the average diameter is comparable between samples, the standard deviation is two times higher in the absence of at low grafting rates (ATP/HSAG $=0$ and $0.005 \mu \mathrm{mol} / \mathrm{mg}$ ).

Table 1. Average diameter and standard deviation of NPs ${ }^{\text {a }}$. Framed data correspond to bimetallic NPs synthesized under identical conditions ( $\mathrm{Cu}_{65} \mathrm{Rh}_{35}$ was obtained with other metal salts concentrations).

\begin{tabular}{|c|c|c|c|}
\hline $\begin{array}{c}\text { ATP/HSAG } \\
\mu \mathrm{mol} / \mathrm{mg}\end{array}$ & $\mathrm{S} / \mathrm{C}$ atomic ratio & $\begin{array}{c}\text { NP diameter } \\
\mathrm{nm}\end{array}$ & $\begin{array}{c}\text { Standard deviation } \\
\mathrm{nm}\end{array}$ \\
\hline \multicolumn{4}{|c|}{ Synthesis Condition 1} \\
\hline $0\left(\mathrm{Cu}_{48} \mathrm{Rh}_{52}\right)$ & 0 & 1.7 & 0.8 \\
\hline 0.005 & 0.0003 & 1.6 & 0.8 \\
\hline 0.05 & 0.0011 & 1.7 & 0.6 \\
\hline 0.5 & 0.0094 & 1.6 & 0.4 \\
\hline 3.3 & 0.018 & 1.7 & 0.4 \\
\hline \multicolumn{5}{|c|}{ Synthesis Condition 2} \\
\hline $0\left(\mathrm{Cu}_{65} \mathrm{Rh}_{35}\right)$ & 0 & 2.2 & 1.0 \\
\hline
\end{tabular}

The size distribution for the non-grafted composite $\left(\mathrm{Cu}_{48} \mathrm{Rh}_{52} / \mathrm{HSAG}\right)$ exhibits the largest size distribution with a peak at $\sim 1.7 \mathrm{~nm}$ followed by a long tail extending up to $5.5 \mathrm{~nm}$. The other non-grafted composite $\mathrm{Cu}_{65} \mathrm{Rh}_{35} / \mathrm{HSAG}$ presents also a larger size distribution than grafted samples (standard deviation of $1 \mathrm{~nm}$ ), together with a larger average size (2.2 vs. 1.7 $\mathrm{nm}$ ). When the grafting rate increases, the distribution becomes narrower (the tail progressive- 
ly disappears) with a standard deviation decreasing by a factor of $2(0.4$ instead of $0.8 \mathrm{~nm}$ for non-grafted sample).

\subsection{Composition}

The bimetallic NPs global composition, determined by ICP-OES and EDS (SEM) is reported in Table 2, as well as the metal contents in wt.\%. There is a good agreement between the compositions given by both methods. A detailed examination of the data obtained under the same synthesis conditions (1) shows that grafting leads to enrichment in copper. NPs obtained with the non-grafted HSAG exhibit a bimetallic global composition of $\mathrm{Cu}_{48} \mathrm{Rh}_{52}$ which eventually reaches $\mathrm{Cu}_{74} \mathrm{Rh}_{26}$ at $3.3 \mu \mathrm{mol} / \mathrm{mg}$. The metal mass fraction (total, wt.\%) is lower than $10 \mathrm{wt} . \%$, this value corresponding to the amount of metal introduced in the synthesis. This indicates that a significant quantity of metal is washed out during the synthetic process. It is particularly the case for the sample grafted at $3.3 \mu \mathrm{mol} / \mathrm{mg}$ (2.6 instead of $10 \mathrm{wt} . \%)$. We assume that, in addition to the loss mentioned above, the grafted aminophenyl layer can lead to the obstruction of some pores of HSAG and thus prevents the access of the metal salt solutions to some fraction of the powder.

Table 2. Composition determined by ICP-OES and EDS (SEM) and metal content in wt.\% (ICP-OES)

\begin{tabular}{|c|c|c|c|c|c|}
\hline $\begin{array}{c}\text { ATP/HSAG } \\
\mu \text { mol/mg }\end{array}$ & $\begin{array}{c}\text { Composition } \\
\mathrm{EDS}\end{array}$ & $\begin{array}{c}\mathrm{Cu} \\
\text { ICP } \%\end{array}$ & $\begin{array}{c}\mathrm{Rh} \\
w t . \%\end{array}$ & $\begin{array}{c}\text { Total } \\
w t . \%\end{array}$ \\
\hline \multicolumn{6}{|c|}{ Synthesis Condition 1} \\
\hline 0 & $\mathrm{Cu}_{53} \mathrm{Rh}_{47}$ & $\mathrm{Cu}_{48} \mathrm{Rh}_{52}$ & 2.0 & 3.6 & 5.6 \\
\hline 0.005 & $\mathrm{Cu}_{58} \mathrm{Rh}_{42}$ & $\mathrm{Cu}_{58} \mathrm{Rh}_{42}$ & 3.3 & 3.9 & 7.2 \\
\hline 0.05 & $\mathrm{Cu}_{68} \mathrm{Rh}_{32}$ & $\mathrm{Cu}_{68} \mathrm{Rh}_{32}$ & 3.1 & 2.4 & 5.5 \\
\hline 0.5 & $\mathrm{Cu}_{68} \mathrm{Rh}_{32}$ & $\mathrm{Cu}_{68} \mathrm{Rh}_{32}$ & 3.9 & 3.0 & 6.9 \\
\hline 3.3 & $\mathrm{Cu}_{73} \mathrm{Rh}_{27}$ & $\mathrm{Cu}_{74} \mathrm{Rh}_{26}$ & 1.9 & 0.7 & 2.6 \\
\hline \multicolumn{5}{|c|}{${\mathrm{Synthesis} \mathrm{Condition}_{2}}^{2}$} \\
\hline 0
\end{tabular}

To characterize more precisely the composites and in particular the variation in composition that can occur within a sample, EDS-TEM has been performed at the level of small groups or aggregates of NPs in many different sample areas. These measures are presented in the Figure 4 (blue diamonds) and compared to the average composition from ICP (red empty squares). 


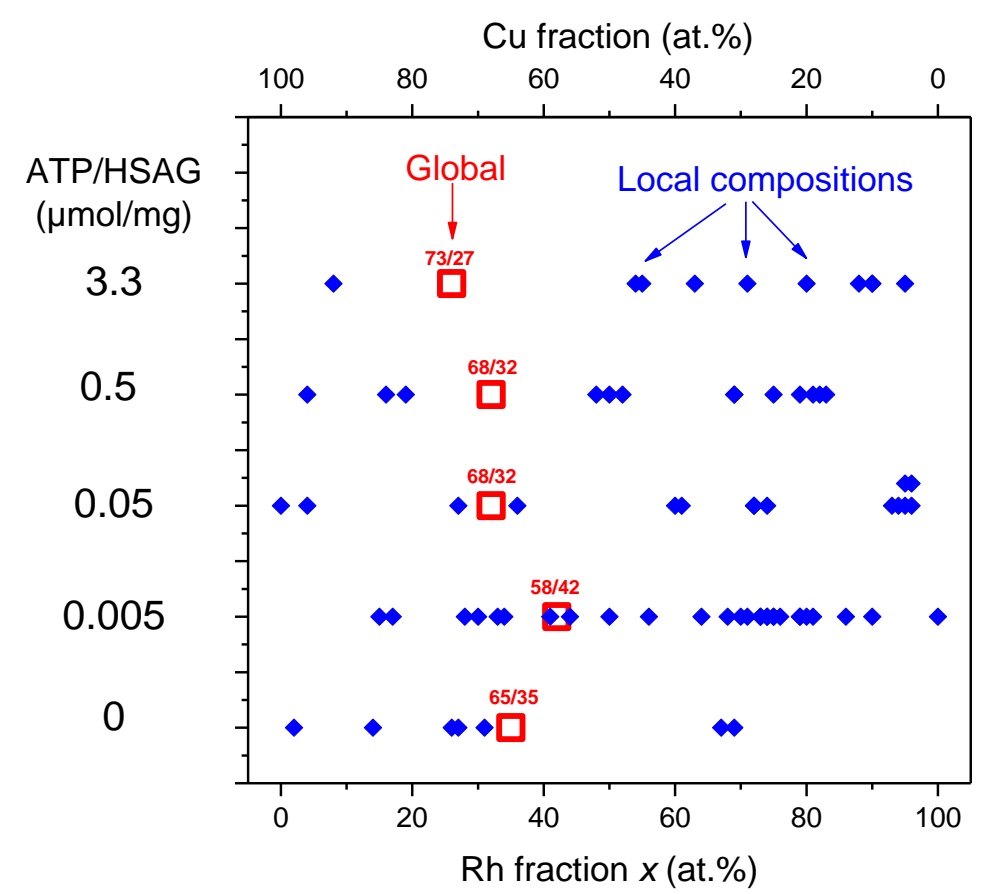

Figure 4. Global (ICP, red squares) and local compositions (EDS-TEM, blue diamonds) of NPs (small groups or aggregates) for the non-grafted sample $\left(0 \mu \mathrm{mol}-\mathrm{Cu}_{65} \mathrm{Rh}_{35}\right)$ and grafted composites.

For the non-grafted sample, the local compositions are separated into two groups, one between 0 and 32 at.\% of $\mathrm{Rh}$, the other around $\sim 68$ at.\% of $\mathrm{Rh}$. The material is therefore inhomogeneous at the nanometer scale with a mixture of copper-rich phases and rhodium-rich phases. On the contrary, the local compositions measured in grafted composites are extremely scattered and often very rich in rhodium (70 to 100 at.\% of Rh). Since the global compositions are more on the $\mathrm{Cu}$ side, this suggests that copper often exists as a pure phase in the composites, which is confirmed by the observation of "rods" on some TEM images that are typical of pure copper-oxides particles (not shown here).

For rhodium- and copper-based compounds, the works of Comisso et al. ${ }^{28}$ on electrodeposited films and of Mirzaei et al. ${ }^{29}$ on nanoparticles have shown that it is difficult to know whether solid solutions are formed (despite the miscibility gap between 20 and 90 at.\% of $\mathrm{Rh}$ ) or whether the compounds consist of various mixtures of limiting phases $\left(\mathrm{Cu}_{10} \mathrm{Rh}_{90}\right.$ and $\mathrm{Cu}_{80} \mathrm{Rh}_{20}$ ). The EDS-TEM measurements at the scale of a few nanometers (small groups of nanoparticles) presented in this study, which show that a wide range of composition is covered, particularly in the case of grafted samples, are more in line with the formation of solid solutions.

Because of the enrichment in copper resulting from grafting, it has been necessary to synthesize a second non-grafted composite (Condition 2) with a global composition matching that of grafted samples, i.e. $\mathrm{Cu}_{65} \mathrm{Rh}_{35} / \mathrm{HSAG}$ (reported in Table 2 and Figure 4), by adjusting 
the metal salt concentrations. This allowed us to compare the effect of grafting on the electrocatalytic activity without interference from changes in composition.

\subsection{Influence of grafting on the capacitive current}

Figure 5 shows the voltammograms recorded with a latex macroelectrode at $1 \mathrm{mVs}^{-1}$ in $\mathrm{KOH} 10^{-1} \mathrm{~mol} \mathrm{~L}^{-1}$ for $\mathrm{Cu}_{100-\mathrm{x}} \mathrm{Rh}_{\mathrm{x}} / \mathrm{HSAG}$ composites with different grafting rate (the current is normalized per mg of composite). The shape of the voltammograms is of rectangular type, typical of large capacitive current from high surface area graphite powders with an additional faradaic component at potentials more negative than $-0.3 \mathrm{~V} / \mathrm{RHE}$. The grafted samples at $0.005,0.05$ and $0.5 \mu \mathrm{mol} / \mathrm{mg}$ exhibit capacitive currents that are larger than that of a nongrafted sample. Thus, for these intermediate coverages, it seems that the grafting procedure leads to an increase in the active surface area. On the other hand, the sample grafted at 3.3 $\mu \mathrm{mol} / \mathrm{mg}$ exhibits the same current than the non-grafted one and this suggests a decrease in surface area. This could be due to the closure of small pores of HSAG by the grafted layer when it becomes too thick. A lower number of pores would be also consistent with the smallest quantity of metal found for this sample compared to others ( $c f$. section 3.3).

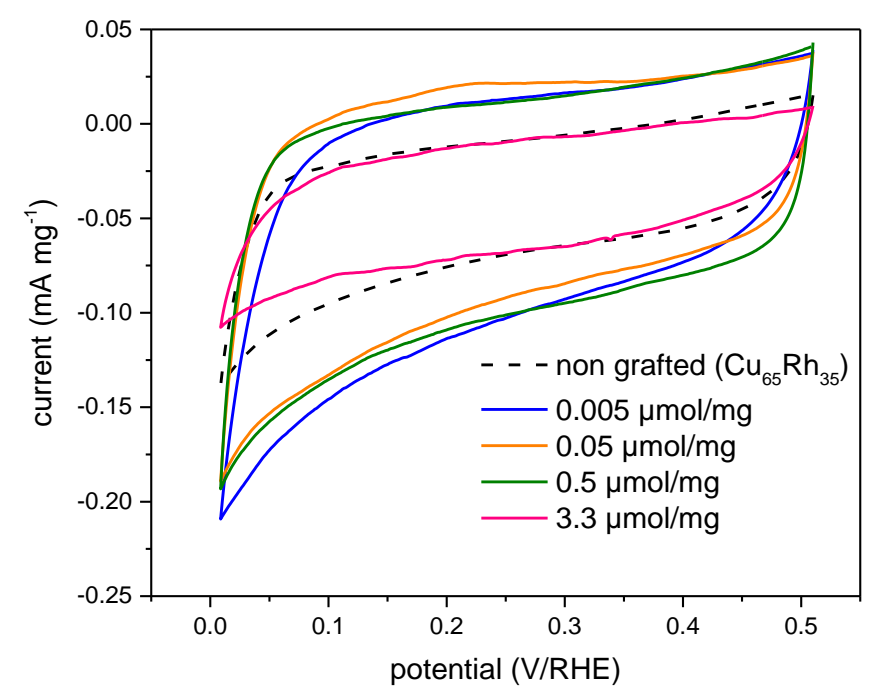

Figure 5. Voltammograms recorded with a latex macroelectrode at $1 \mathrm{mVs}^{-1}$ in $\mathrm{KOH} 10^{-1} \mathrm{~mol} \mathrm{~L}^{-1}$ for the $\mathrm{Cu}_{100-\mathrm{x}} \mathrm{Rh}_{\mathrm{x}} / \mathrm{HSAG}$ composites for different grafting.

These results obtained on latex macroelectrode with well known quantity of composites will be useful for the normalization of the voltammograms obtained with the cavity microelectrode ( $c f . \mathrm{CV}$ normalization in the Experimental section). 


\subsection{Electrochemical reduction of nitrate on bimetallic RhCu/HSAG composites}

Figure 6 shows the voltammograms recorded with a $\mathrm{CME}$ in $\mathrm{KOH} 10^{-1} \mathrm{~mol} \mathrm{~L}^{-1}$ and $\mathrm{KNO}_{3} 10^{-2} \mathrm{~mol} \mathrm{~L}^{-1}$ for the different samples $\mathrm{Cu}_{100-\mathrm{x}} \mathrm{Rh}_{\mathrm{x}} / \mathrm{HSAG}$ with (a) grafted carbons with various coverages and (b) non-grafted carbon for comparison. Currents of the normalized CVs ( $c f$. Experimental section) versus the ATP concentration used during synthesis are then reported in the graph of Figure $\mathbf{6 c}$ and the potentials are given as inserted tables in Figure 6(a) and b.

For the sample grafted at $0.005 \mu \mathrm{mol} / \mathrm{mg}$ (Figure 6(a)), the voltammogram presents a well-defined shape with a unique cathodic peak located at $0.059 \mathrm{~V} / \mathrm{RHE}$ exhibiting the maximum intensity among all samples. As the rate of grafting is increased, the peak intensity gradually decreases until reaching zero at $3.3 \mu \mathrm{mol} / \mathrm{mg}$. At the same time, the peak potential shifts towards lower values. This evolution shows that the electrochemical reduction of nitrates catalyzed at the surface of $\mathrm{Cu}_{100-\mathrm{x}} \mathrm{Rh}_{\mathrm{x}} \mathrm{NPs}$ gets inhibited at high surface coverage (Figure 6). This is consistent with a higher grafting density of aryl groups (Fig. 2c) that isolate the metal NPs (synthesized on the top of it) from the graphite surface (insulating effect).

Results obtained with grafted samples are now compared with those found for (nongrafted) $\mathrm{Cu}_{48} \mathrm{Rh}_{52}$ (same synthesis conditions) and $\mathrm{Cu}_{65} \mathrm{Rh}_{35}$ (same global composition). Previous works have shown that the mechanism for reducing nitrates in alkaline media on bimetallics such as $\mathrm{CuPd}$ and $\mathrm{CuRh}$ is of the same nature and consists of a first step of reducing nitrates to nitrites catalyzed by copper followed by a reduction of nitrites to ammonia (via hydroxylamine formation) catalyzed by palladium ${ }^{1}$ or rhodium ${ }^{29}$. The voltammograms of these two samples exhibit two peaks that could therefore be assigned to the reduction of nitrate to nitrite $\left(\mathrm{E}_{1}\right)$ and to the further reduction of nitrite to hydroxylamine and ammoniac $\left(\mathrm{E}_{2}\right)$. 

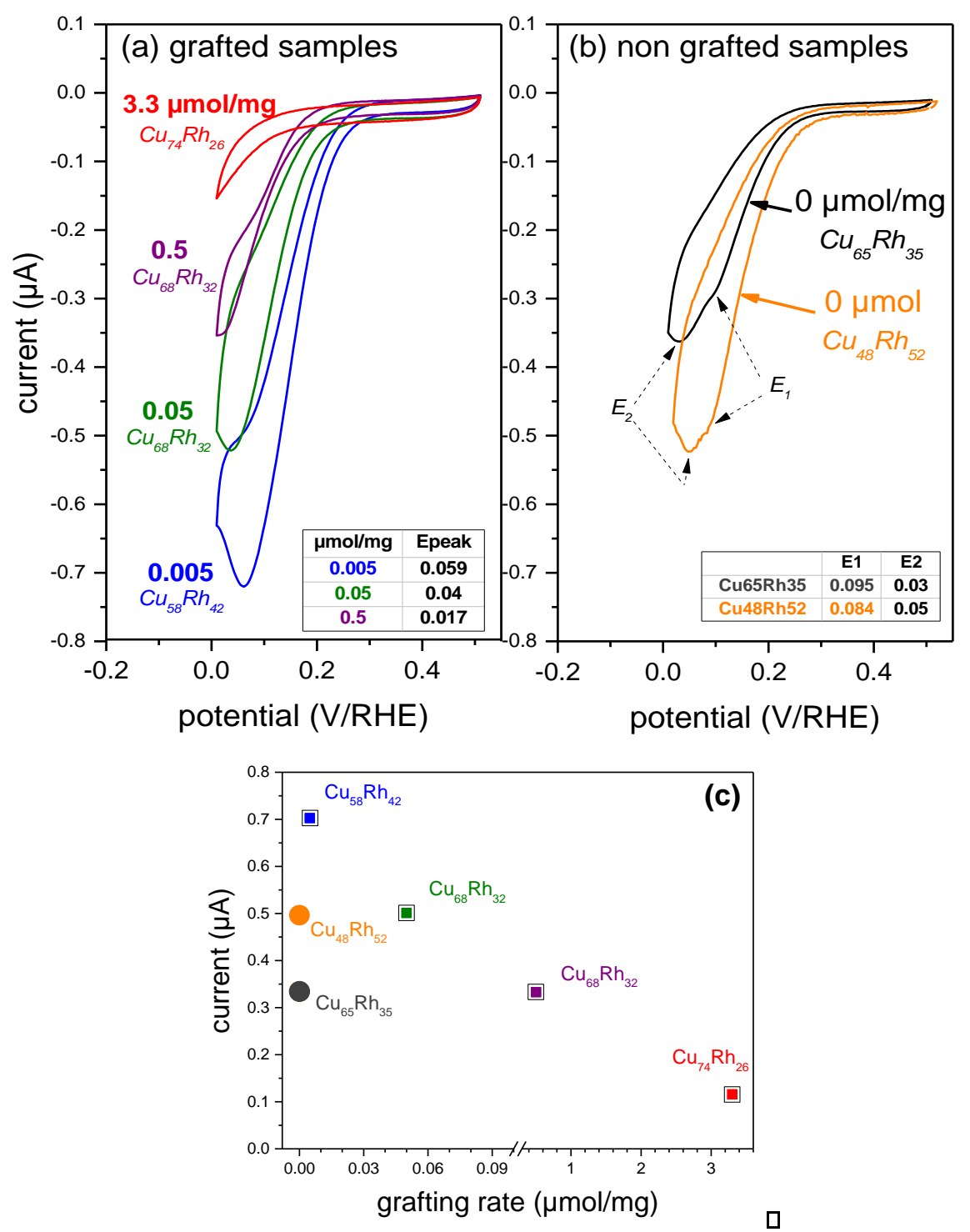

Figure 6. Voltammograms recorded with a $\mathrm{CME}$ at $10 \mathrm{mVs}^{-1}$ in $\mathrm{KOH} 10^{-1} \mathrm{~mol} \mathrm{~L}^{-1}$ and $\mathrm{KNO}_{3} 10^{-2}$ mol L ${ }^{-1}$ for the $\mathrm{Cu}_{100-\mathrm{x}} \mathrm{Rh}_{\mathrm{x}} / \mathrm{HSAG}$ composites for different grafting (a) and with no grafting for comparison (b). (c) Evolution of the intensity versus the grafting rate (circles = no grafting; squares = with various grafting rate of HSAG).

In comparison, only one peak is observed for grafted composites. Moreover, the peak intensity of the sample grafted at $0.005 \mu \mathrm{mol} / \mathrm{mg}$ is higher than that of $E_{2}$ of the (non-grafted) $\mathrm{Cu}_{48} \mathrm{Rh}_{52} / \mathrm{HSAG}$ composite by $40 \%$. This is surprising since $\mathrm{Cu}_{48} \mathrm{Rh}_{52}$ has the highest electrocatalytic activity for nitrate reduction for these $\mathrm{CuRh}$ NPs/HSAG electrocatalysts, i.e. it is at the top of a volcano plot established as a function of the composition (peak current with $\mathrm{Cu}_{58} \mathrm{Rh}_{42} 25 \%$ lower) ${ }^{29}$. This gain in current intensity cannot be explained by a size effect since the NP characteristics for these two samples are similar ( $c f$. Table 1). Moreover, the shape of the voltammograms differs significantly ( 1 peak for the grafted sample instead of 2 for non-grafted one) which indicates a more fundamental difference in the catalyst properties. We assume that this is related to the fact that grafting induces changes of the local composi- 
tion as observed from the EDS-TEM analysis (Figure 4). While the non-grafted sample contains basically a mixture of two phases, one being copper-rich ( 0 to 32 at.\% of $\mathrm{Rh}$ ) and the other rhodium-rich ( $68 \%$ at.\% of $\mathrm{Rh})$, the grafted samples exhibit local compositions that are spread over the entire composition domain, with in particular intermediate and very rich rhodium phases ( $\sim 50$ at. $\%$ and $>70$ at. $\%$ of $\mathrm{Rh}$, respectively) that are not found in the nongrafted counterpart. This is consistent with our previous observation that the reduction of nitrite is the most efficient on pure rhodium compared to any $\mathrm{CuRh}$ bimetallic ${ }^{29}$.

Another finding lies in the fact that the grafted composite $\mathrm{Cu}_{68} \mathrm{Rh}_{32} / \mathrm{HSAG}$ (at $0.05 \mu \mathrm{mol} / \mathrm{mg}$ ) exhibits a peak with the same intensity than that of (non-grafted) $\mathrm{Cu}_{42} \mathrm{Rh}_{52} / \mathrm{HSAG}$ of optimal composition. Eventually, it must also be noted that for two composites with identical global bimetallic compositions (grafted $\mathrm{Cu}_{68} \mathrm{Rh}_{32} / \mathrm{HSAG}$ and nongrafted $\mathrm{Cu}_{65} \mathrm{Rh}_{35} / \mathrm{C}$ ), the grafted sample exhibit a peak current intensity higher by $44 \%$. In this latter case, however, the difference could also arise from the lower and narrower average NP size obtained with grafted HSAG $(1.7 \pm 0.6 \mathrm{~nm}$ instead of $2.2 \pm 1.0 \mathrm{~nm}, c f$. Table 1$)$ which should result in a higher total surface area of the metal catalyst.

Grafting HSAG with benzenethiol groups therefore seems to have two positive effects on the electrochemical properties of $\mathrm{CuRh}$ bimetallic nanoparticles-based composites. On the one hand, it makes it possible in some cases to obtain a smaller and more monodisperse size of nanoparticles, which increases the total active surface area, and on the other hand the local composition of nanoparticles varies over a larger composition range, which improves the catalytic effect. This second effect remains to be investigated and understood in the light of the reaction mechanisms described in other works ${ }^{28,29}$.

Finally, it must be emphasized that there is still room for improvement in the proposed approach of grafting so as to reach even higher electrocatalytic currents in the reduction of nitrate. First, the rate of grafting could be further reduced since it is the lower rate that leads to the highest current. Second, the metal salt concentrations can be further optimized in order to obtain a global composition close to the optimum value $\left(\mathrm{Cu}_{48} \mathrm{Rh}_{52}\right)$ for the reduction of nitrates with grafted HSAG.

\section{Conclusion}

Various composites made of bimetallic $\mathrm{Cu}_{100-\mathrm{x}} \mathrm{Rh}_{\mathrm{x}}$ nanoparticles (NPs) dispersed in benzenethiol grafted HSAG powders have been synthesized. This was performed by first functionalizing HSAG with in situ generated diazonium salts at different rates, then impreg- 
nating the grafted HSAG with an aqueous solution of $\mathrm{Cu}$ and $\mathrm{Rh}$ salts and a surfactant (CTAB).

For all grafted composites, the average NPs size was $\sim 1.7 \mathrm{~nm}$ but with a size distribution becoming narrower under increasing grafting rate. Compared to non-grafted composites synthesized under the same conditions, grafting is found to induce enrichment in $\mathrm{Cu}$. However, the local composition measured by EDS-TEM at the level of little NP aggregates varies extensively and is richer in rhodium than the global composition, which is also consistent with the presence of pure copper elements in the samples. On the contrary, the non-grafted sample have a narrower composition range with more distinct copper-rich and rhodium-rich areas.

Voltammetry studies on nitrate reduction in alkaline media have been performed with a cavity microelectrode for grafted and non-grafted composites. Increasing the grafting rate leads to a lowering of the peak current intensities and a shift of peak potentials towards cathodic values, probably because the grafting layer becomes thicker which insulates the NPs from HSAG. However, at the lower grafting rate $(0.005 \mu \mathrm{mol} / \mathrm{mg})$, a $40 \%$ gain in current intensity is obtained compared to a non-grafted sample synthesized in the same conditions. This improvement occurs despite a non-optimal composition for nitrate reduction on $\mathrm{CuRh}$ bimetallics. There is room to further improve the electrocatalytic properties of $\mathrm{Cu}_{100-\mathrm{x}} \mathrm{Rh}_{\mathrm{x}}$ NPs/grafted HSAG composites by optimizing the grafting rate and the bimetallic composition.

The voltammogram characteristics (number of peaks) are also clearly modified by grafting benzenethiol groups. These modifications are not related to the improved NP size monodispersity but are likely the result of variations in local composition of the phases existing at the nanoscale. This finding opens new perspectives in the understanding and control of the efficiency of bimetallic electrocatalysts.

Acknowledgements. The authors acknowledge the support of the Centre National de la Recherche Scientifique and the University Paris-Est Créteil through the CARE transverse project (Carbon-Aryl-Rhodium-based hybrids for the Environment). P. Mirzaei acknowledges MBA Water Treatment Chemicals Co. for the financial support of his $\mathrm{PhD}$.

\section{References}

(1) Duca, M.; Koper, M. T. M. Powering Denitrification: The Perspectives of Electrocatalytic Nitrate Reduction. Energy Environ. Sci. 2012, 5 (12), 9726. https://doi.org/10.1039/c2ee23062c. 
(2) Heck, K. N.; Garcia-Segura, S.; Westerhoff, P.; Wong, M. S. Catalytic Converters for Water Treatment. Acc. Chem. Res. 2019, 52 (4), 906-915. https://doi.org/10.1021/acs.accounts.8b00642.

(3) Wildgoose, G. G.; Banks, C. E.; Leventis, H. C.; Compton, R. G. Chemically Modified Carbon Nanotubes for Use in Electroanalysis. Microchim. Acta 2006, 152 (3), 187214. https://doi.org/10.1007/s00604-005-0449-x.

(4) Urchaga, P.; Weissmann, M.; Baranton, S.; Girardeau, T.; Coutanceau, C. Improvement of the Platinum Nanoparticles-Carbon Substrate Interaction by Insertion of a Thiophenol Molecular Bridge. Langmuir 2009, 25 (11), 6543-6550. https://doi.org/10.1021/la9000973.

(5) Belbekhouche, S.; Kebe, S. I.; Mahouche-Chergui, S.; Guerrouache, M.; Carbonnier, B.; Jaziri, M.; Chehimi, M. M. Aryl Diazonium-Modified Olive Waste: A Low Cost Support for the Immobilization of Nanocatalysts. Colloids Surf. Physicochem. Eng. Asp. 2017, 529, 541-549. https://doi.org/10.1016/j.colsurfa.2017.06.011.

(6) Zeb, G.; Gaskell, P.; Le, X. T.; Xiao, X.; Szkopek, T.; Cerruti, M. Decoration of Graphitic Surfaces with Sn Nanoparticles through Surface Functionalization Using Diazonium Chemistry. Langmuir 2012, 28 (36), 13042-13050. https://doi.org/10.1021/la302162c.

(7) González, M. C. R.; Orive, A. G.; Salvarezza, R. C.; Creus, A. H. Electrodeposition of Gold Nanoparticles on Aryl Diazonium Monolayer Functionalized HOPG Surfaces. Phys. Chem. Chem. Phys. 2016, 18 (3), 1953-1960. https://doi.org/10.1039/C5CP06415E.

(8) Bayati, M.; Abad, J. M.; Bridges, C. A.; Rosseinsky, M. J.; Schiffrin, D. J. Size Control and Electrocatalytic Properties of Chemically Synthesized Platinum Nanoparticles Grown on Functionalised HOPG. J. Electroanal. Chem. 2008, 623 (1), 19-28. https://doi.org/10.1016/j.jelechem.2008.06.011.

(9) Al-Akraa, I. M.; Mohammad, A. M.; El-Deab, M. S.; El-Anadouli, B. E. FlowerShaped Gold Nanoparticles: Preparation, Characterization, and Electrocatalytic Application. Arab. J. Chem. 2017, 10 (6), 877-884. https://doi.org/10.1016/j.arabjc.2015.05.004.

(10) Rabti, A.; Hannachi, A.; Maghraoui-Meherzi, H.; Raouafi, N. FerroceneFunctionalized Carbon Nanotubes: An Adsorbent for Rhodamine B. Chem. Afr. 2019, 2 (1), 113-122. https://doi.org/10.1007/s42250-018-00031-0.

(11) Abdolmaleki, A.; Mallakpour, S.; Mahmoudian, M.; Kamali, S.; Zhiani, M.; Rezaei, B.; Jahromi, A. R. T. Functionalization of Graphite with the Diels-Alder Reaction to Fabricate Metal-Free Electrocatalysts for Highly Efficient Hydrogen Evolution Reaction. ChemistrySelect 2018, 3 (46), 13070-13075. https://doi.org/10.1002/slct.201802701.

(12) Yan, F.; Jiang, Y.; Sun, X.; Bai, Z.; Zhang, Y.; Zhou, X. Surface Modification and Chemical Functionalization of Carbon Dots: A Review. Microchim. Acta 2018, 185 (9), 424. https://doi.org/10.1007/s00604-018-2953-9.

(13) Jodeh, S.; Ibsharat, I.; Khalaf, B.; Hamed, O.; Jodeh, D.; Omar, D. The Use of Magnetic Multiwalled Carbon Nanotubes Functionalized with Chitosan for Nitrate Removal from Wastewater. Chem. Afr. 2019. https://doi.org/10.1007/s42250-019-00056-z.

(14) Bahr, J. L.; Yang, J.; Kosynkin, D. V.; Bronikowski, M. J.; Smalley, R. E.; Tour, J. M. Functionalization of Carbon Nanotubes by Electrochemical Reduction of Aryl Diazonium Salts: A Bucky Paper Electrode. J. Am. Chem. Soc. 2001, 123 (27), 6536-6542. https://doi.org/10.1021/ja010462s.

(15) Mahouche-Chergui, S.; Gam-Derouich, S.; Mangeney, C.; Chehimi, M. M. Aryl Diazonium Salts: A New Class of Coupling Agents for Bonding Polymers, Biomacromolecules and Nanoparticles to Surfaces. Chem. Soc. Rev. 2011, 40 (7), 4143-4166. https://doi.org/10.1039/c0cs00179a. 
(16) Luksirikul, P.; Tedsree, K.; Moloney, M. G.; Green, M. L. H.; Tsang, S. C. E. Electron Promotion by Surface Functional Groups of Single Wall Carbon Nanotubes to Overlying Metal Particles in a Fuel-Cell Catalyst. Angew. Chem. Int. Ed. 2012, 51 (28), 69987001. https://doi.org/10.1002/anie.201201589.

(17) McCreery, R. L. Advanced Carbon Electrode Materials for Molecular Electrochemistry. Chem. Rev. 2008, 108 (7), 2646-2687. https://doi.org/10.1021/cr068076m.

(18) Ossonon, B. D.; Bélanger, D. Functionalization of Graphene Sheets by the Diazonium Chemistry during Electrochemical Exfoliation of Graphite. Carbon 2017, 111, 83-93. https://doi.org/10.1016/j.carbon.2016.09.063.

(19) Bensghaïer, A.; Lau Truong, S.; Seydou, M.; Lamouri, A.; Leroy, E.; Mičušik, M.; Forro, K.; Beji, M.; Pinson, J.; Omastová, M.; et al. Efficient Covalent Modification of Multiwalled Carbon Nanotubes with Diazotized Dyes in Water at Room Temperature. Langmuir 2017, 33 (27), 6677-6690. https://doi.org/10.1021/acs.langmuir.7b00711.

(20) Mohamed, A. A.; Salmi, Z.; Dahoumane, S. A.; Mekki, A.; Carbonnier, B.; Chehimi, M. M. Functionalization of Nanomaterials with Aryldiazonium Salts. Adv. Colloid Interface Sci. 2015, 225, 16-36. https://doi.org/10.1016/j.cis.2015.07.011.

(21) Fernández-García, L.; Blanco, M.; Blanco, C.; Álvarez, P.; Granda, M.; Santamaría, R.; Menéndez, R. Graphene Anchored Palladium Complex as Efficient and Recyclable Catalyst in the Heck Cross-Coupling Reaction. J. Mol. Catal. Chem. 2016, 416, 140146. https://doi.org/10.1016/j.molcata.2016.02.023.

(22) Ünal, Ö. F.; Yeşildăg, A.; Ekinci, D. Synthesis of Gold Nanoparticles on DiazoniumGenerated Heteroaryl Films and Their Electrocatalytic Activities. Electrochimica Acta 2018, 290, 474-486. https://doi.org/10.1016/j.electacta.2018.09.083.

(23) Rodríguez González, M. C.; Rivera, L. M.; Pastor, E.; Hernández Creus, A.; García, G. A Facile Method for the Fabrication of Hierarchical Nanosized Metal Catalysts. $J$. Catal. 2018, 366, 1-7. https://doi.org/10.1016/j.jcat.2018.07.025.

(24) Guo, D. J.; Li, H. L. Highly Dispersed Ag Nanoparticles on Functional MWNT Surfaces for Methanol Oxidation in Alkaline Solution. Carbon 2005, 43 (6), 1259-1264. https://doi.org/10.1016/j.carbon.2004.12.021.

(25) Liu, W.; Wang, X.; Fu, S. Process for Producing Copper Nanoparticles. US7422620B2, September 9, 2008.

(26) Kankla, P.; Limtrakul, J.; Green, M. L. H.; Chanlek, N.; Luksirikul, P. Electrooxidation of Formic Acid Enhanced by Surfactant-Free Palladium Nanocubes on Surface Modified Graphene Catalyst. Appl. Surf. Sci. 2019, 471, 176-184. https://doi.org/10.1016/j.apsusc.2018.12.001.

(27) Vilà, N.; Brussel, M. V.; D’Amours, M.; Marwan, J.; Buess-Herman, C.; Bélanger, D. Metallic and Bimetallic Cu/Pt Species Supported on Carbon Surfaces by Means of Substituted Phenyl Groups. J. Electroanal. Chem. 2007, 609 (2), 85-93. https://doi.org/10.1016/j.jelechem.2007.06.026.

(28) Comisso, N.; Cattarin, S.; Fiameni, S.; Gerbasi, R.; Mattarozzi, L.; Musiani, M.; Vázquez-Gómez, L.; Verlato, E. Electrodeposition of $\mathrm{Cu}-\mathrm{Rh}$ Alloys and Their Use as Cathodes for Nitrate Reduction. Electrochem. Commun. 2012, 25, 91-93. https://doi.org/10.1016/j.elecom.2012.09.026.

(29) Mirzaei, P.; Bastide, S.; Aghajani, A.; Bourgon, J.; Zlotea, C.; Laurent, M.; Latroche, M.; Cachet-Vivier, C. Electrocatalytic Reduction of Nitrate and Nitrite at CuRh Nanoparticles/C Composite Electrodes. Electrocatalysis 2018, 9 (3), 343-351. https://doi.org/10.1007/s12678-017-0437-z.

(30) Mirkhalaf, F.; Graves, J. E. Nanostructured Electrocatalysts Immobilised on Electrode Surfaces and Organic Film Templates. Chem. Pap. 2012, 66 (5), 472-483. https://doi.org/10.2478/s11696-011-0110-6. 
(31) Liu, G.; Luais, E.; Gooding, J. J. The Fabrication of Stable Gold Nanoparticle-Modified Interfaces for Electrochemistry. Langmuir 2011, 27 (7), 4176-4183. https://doi.org/10.1021/la104373v.

(32) Bélanger, D.; Pinson, J. Electrografting: A Powerful Method for Surface Modification. Chem. Soc. Rev. 2011, 40 (7), 3995-4048. https://doi.org/10.1039/C0CS00149J.

(33) Combellas, C.; Kanoufi, F.; Pinson, J.; Podvorica, F. I. Time-of-Flight Secondary Ion Mass Spectroscopy Characterization of the Covalent Bonding between a Carbon Surface and Aryl Groups. Langmuir 2005, 21 (1), 280-286. https://doi.org/10.1021/la0481061.

(34) Schneider, C. A.; Rasband, W. S.; Eliceiri, K. W. NIH Image to ImageJ: 25 Years of Image Analysis. Nat. Methods 2012, 9 (7), 671-675. https://doi.org/10.1038/nmeth.2089.

(35) Cliff, G.; Lorimer, G.W. The Quantitative Analysis of Thin Specimen. J. Microsc. 1975, 103 (2), 203-207.

(36) Cachet-Vivier, C.; Keddam, M.; Vivier, V.; Yu, L. T. Development of Cavity Microelectrode Devices and Their Uses in Various Research Fields. J. Electroanal. Chem. 2013, 688, 12-19. https://doi.org/10.1016/j.jelechem.2012.09.011.

(37) Blacha, A.; Koscielniak, P.; Sitarz, M.; Szuber, J.; Zak, J. Pedot Brushes Electrochemically Synthesized on Thienyl-Modified Glassy Carbon Surfaces. Electrochimica Acta 2012, 62, 441-446. https://doi.org/10.1016/j.electacta.2011.12.063.

(38) Hinrichs, K.; Roodenko, K.; Rappich, J.; Chehimi, M. M.; Pinson, J. Analytical Methods for the Characterization of Aryl Layers. In Aryl Diazonium Salts; John Wiley \& Sons, Ltd, 2012; pp 71-101. https://doi.org/10.1002/9783527650446.ch4.

(39) Tarlov, M. J.; Newman, J. G. Static Secondary Ion Mass Spectrometry of SelfAssembled Alkanethiol Monolayers on Gold. Langmuir 1992, 8 (5), 1398-1405. https://doi.org/10.1021/la00041a026.

(40) Huang, J.; Hemminger, J. C. Photooxidation of Thiols in Self-Assembled Monolayers on Gold. J. Am. Chem. Soc. 1993, 115 (8), 3342-3343. https://doi.org/10.1021/ja00061a048.

(41) Biesinger, M. C. Advanced Analysis of Copper X-Ray Photoelectron Spectra. Surf. Interface Anal. 2017, 49 (13), 1325-1334. https://doi.org/10.1002/sia.6239.

(42) Dennis, A. M.; Howard, R. A.; Kadish, K. M.; Bear, J. L.; Brace, J.; Winograd, N. XRay Photoelectron Spectra of Some Dirhodium Carboxylate Complexes. Inorganica Chim. Acta 1980, 44, L139-L141. https://doi.org/10.1016/S0020-1693(00)90981-2.

(43) Okamoto, Y.; Ishida, N.; Imanaka, T.; Teranishi, S. Active States of Rhodium in Rhodium Exchanged Y Zeolite Catalysts for Hydrogenation of Ethylene and Acetylene and Dimerization of Ethylene Studied with X-Ray Photoelectron Spectroscopy. J. Catal. 1979, 58 (1), 82-94. https://doi.org/10.1016/0021-9517(79)90247-1.

(44) Vallet, C. E.; Choudhury, A.; Sobol, P. E.; White, C. W. XPS Characterization of Anodic Layers Grown on Ir- and Rh-Implanted Titanium. Electrochimica Acta 1993, 38 (10), 1313-1320. https://doi.org/10.1016/0013-4686(93)80064-7.

(45) Harnisch, J. A.; Pris, A. D.; Porter, M. D. Attachment of Gold Nanoparticles to Glassy Carbon Electrodes via a Mercaptobenzene Film. J. Am. Chem. Soc. 2001, 123 (24), 5829-5830. https://doi.org/10.1021/ja010564i. 
Graphical Abstract
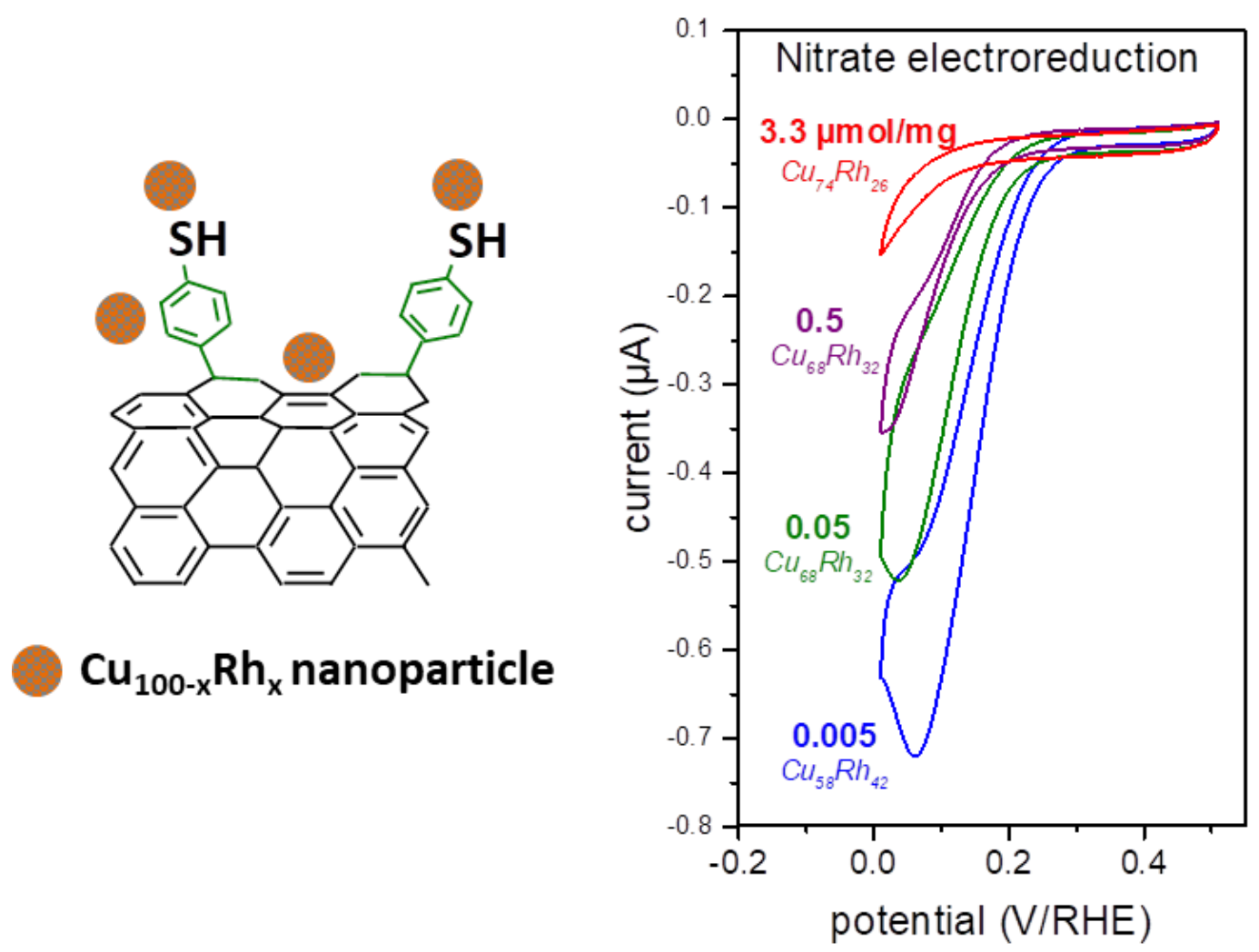